\title{
Algoritma C4.5 pada Registrasi Pasien
}

\section{DEWI ROSMALA, RIZANDI NUGRO LIBRANTO}

\author{
Jurusan Teknik Informatika, Fakultas Teknologi Industri, \\ Institut Teknologi Nasional Bandung \\ Email: d_rosmala@itenas.ac.id
}

\begin{abstract}
ABSTRAK
Algoritma C4.5 merupakan algoritma yang digunakan untuk membentuk pohon keputusan. Klinik dan Rumah Bersalin Melong Asih yang bertempat di Cimahi, bertugas melayani pemeriksaan umum, konsultasi masalah kandungan serta pemeriksaan ibu hamil. Proses registrasi yang panjang dapat menimbulkan antrian yang menyebabkan ketidaknyamanan pasien. Melihat kondisi tersebut diperlukan suatu sistem registrasi pada paisen untuk memprediksi waktu antrian di Klinik dan Rumah Bersalin Melong Asih. Data yang dimanfaatkan adalah data Rekam Medis Pasien (yang digunakan sebagai data training dan data testing). Data keluhan tersebut diproses menggunakan decision tree sehingga dapat menghasilkan suatu keputusan waktu penanganan pasien yang diterjemahkan ke dalam bahasa linguistik yaitu, cepat, sedang, dan lama. Partisi data 90:10 merupakan partisi terbaik karena memiliki nilai precision, recall, dan accuracy yang paling tinggi daripada partisi lainnya.
\end{abstract}

Kata kunci : Registrasi Pasien, Klasifikasi, Prediksi, Algoritma C.45, Decision Tree

\section{ABSTRACT}

C4.5 algorithm is an algorithm that is used to form the decision tree. Clinic and Maternity Home Melong Asih housed in Cimahi, duty to serve the public examination, consultation and examination of the problems womb of pregnant women. Lengthy registration process can lead to queues that cause patient discomfort. Seeing these conditions we need a registration system for patients to predict the queuing time at the Clinic and Maternity Hospital Melong Asih. The data will be used here is data Patient Medical Record (which will be used as training data and data testing). The complaint data is processed using a decision tree that can produce a decision when handling patients who translated into linguistics, namely, fast, medium, and long. 90:10 is the best partition because it has the precision, recall, and the highest accuracy than other partitions.

Keywords : Registration Patient, Classification, Prediction, C4.5 Algorithm, Decision Tree 


\section{PENDAHULUAN}

Klinik dan Rumah Bersalin Melong Asih yang bertempat di Cimahi, bertugas melayani pemeriksaan umum, konsultasi masalah kandungan serta pemeriksaan ibu hamil. Proses registrasi yang panjang dapat menimbulkan masalah ketidaknyamanan pada pasien. Melihat kondisi tersebut diperlukan suatu sistem registrasi pasien untuk memprediksi waktu antrian di Klinik dan Rumah Bersalin Melong Asih. Data yang dimanfaatkan adalah data Rekam Medis Pasien (yang digunakan sebagai data training dan data testing). Dengan memanfaatkan data pasien, Algoritma C4.5 digunakan untuk memprediksi waktu pemeriksaan pasien yang digunakan dalam registrasi.

Dibutuhkan suatu teknik klasifikasi yang merupakan salah satu teknik untuk menganalisis data pasien tersebut. Algoritma C4.5 merupakan salah satu algoritma Decision Tree yang dapat digunakan untuk memprediksi suatu kejadian, algoritma ini merupakan salah satu algoritma induksi pohon keputusan yang dikembangkan oleh J. Ross Quinlan ${ }^{[1]}$. Pemanfaatan Algoritma C4.5 pada sistem digunakan pada fitur registrasi pasien untuk proses penentuan atau prediksi waktu penanganan pasien, metode ini menentukan waktu penanganan dengan melihat keluhan yang dialami oleh pasien. Data keluhan tersebut diproses menggunakan Decision Tree sehingga dapat menghasilkan suatu keputusan waktu penanganan pasien yang diterjemahkan ke dalam bahasa linguistik yaitu, cepat, sedang, dan lama. Pasien dapat melakukan pendaftaran secara online dengan mengisi data pendaftaran dan keluhan yang dialami, kemudian pasien dapat melihat nomer antrian dan waktu pemeriksaan pada website, sehingga pasien tersebut dapat menunggu di rumah sampai dengan waktu periksa yang telah ditentukan.

\section{METODOLOGI PENELITIAN}

Metode yang digunakan dalam penelitian ini yaitu, studi pustaka terhadap sumber-sumber yang mendukung penelitian ini, analisis Algoritma C4.5 dalam penentuan registrasi pemeriksaan pasien, perancangan terhadap perangkat lunak (website) yang dibangun berdasarkan hasil yang diperoleh tahap analisis, implementasi terhadap perangkat lunak yang dibangun berdasarkan hasil yang diperoleh pada tahap perancangan, kemudian pengujian dan evaluasi terhadap hasil yang diperoleh berdasarkan kasus yang diteliti.

\subsection{Pengumpulan Data}

Data primer adalah data yang diperoleh langsung dari sumbernya dengan melakukan wawancara dan survei langsung di tempat penelitian. Data primer yang dibutuhkan pada penelitian ini seperti data pasien, data rekam medis pasien untuk menentukan attribut dalam pembuatan sistem, alur kerja pada Klinik dan Rumah Bersalin untuk menentukan fitur-fitur yang dibangun pada sistem, serta data set yang digunakan sebagai data training dan data testing dalam penerapan Algoritma C4.5 untuk menentukan waktu pemeriksaan pasien. Data set yang dibutuhkan dalam penelitian ini memiliki beberapa attribut dan kelas. Attribut yang digunakan terdiri umur, kontrol kehamilan, dan tujuh belas keluhan pasien yang sering terjadi pada klinik bersalin tempat penelitian. Sedangkan data sekunder adalah data yang diperoleh secara tidak langsung bersumber dari dokumentasi, literatur, buku, jurnal dan informasi lainnya yang ada hubungannya dengan masalah yang diteliti. Data sekunder pada penelitian ini adalah : buku-buku, jurnal tentang Algoritma Decision Tree C4.5.

\subsection{Sumber Data}

Dari data yang ada, kolom yang diambil sebagai attribut atau variabel keputusan adalah kolom waktu. Attribut-attribut yang digunakan sebagai variabel penentu dalam pembentukan pohon keputusan adalah Kontrol Hamil Keluhan, Sakit Kepala, Batuk/Demam, Mual, Muntah, 
Mulas, Sakit Perut/Pinggang, Sering Cape, Telat/Haid, Keputihan, Pendarahan, Keluar Cairan Ketuban, Kelar Lendir/Flek, Suntik KB, Pasang/Kontrol IUD, Ingin Hamil, Gerakan Bayi.

Data set yang dibutuhkan dalam penelitian ini memiliki beberapa attribut dan kelas. Attribut yang digunakan terdiri umur, kontrol kehamilan, dan tujuh belas keluhan pasien yang sering terjadi pada klinik bersalin tempat penelitian. Berikut merupakan attribut dan nilai dari attribut yang digunakan sebagai data set pada penelitian ini.

Tabel 1. Attribut dan Nilai Attribut

\begin{tabular}{|c|l|c|}
\hline No & \multicolumn{1}{|c|}{ Attribut } & Nilai \\
\hline 1 & Umur & Numeris \\
\hline 2 & Kontrol Hamil dan Keluhan & Ya atau Tidak \\
\hline 3 & Sakit Kepala & Ya atau Tidak \\
\hline 4 & Batuk / Demam & Ya atau Tidak \\
\hline 5 & Mual & Ya atau Tidak \\
\hline 6 & Muntah & Ya atau Tidak \\
\hline 7 & Mulas & Ya atau Tidak \\
\hline 8 & Sakit Perut / Pinggang & Ya atau Tidak \\
\hline 9 & Sering Cape & Ya atau Tidak \\
\hline 10 & Telat / Nyeri Haid & Ya atau Tidak \\
\hline 11 & Keputihan & Ya atau Tidak \\
\hline 12 & Pendarahan & Ya atau Tidak \\
\hline 13 & Keluar Cairan Ketuban & Ya atau Tidak \\
\hline 14 & Keluar Lendir / Flek & Ya atau Tidak \\
\hline 15 & Suntik Kb & Ya atau Tidak \\
\hline 16 & Pasang / Kontrol Iud & Ya atau Tidak \\
\hline 17 & Ingin Hamil & Ya atau Tidak \\
\hline 18 & Gerakan Bayi & Ya atau Tidak \\
\hline 19 & Usia Kehamilan & \\
\hline
\end{tabular}

Sumber : (Hasil Analisis,2016)

Kelas pada data set yang digunakan pada penelitian ini berupa kelas waktu yang merupakan lama waktu dari pemeriksaan pasien terdiri dari tiga kategori yaitu, cepat, sedang, dan lama. Penentuan kategori tersebut merupakan hasil konversi dari bentuk waktu dalam satuan menit. Jika pemeriksaan pasien kurang dari sepuluh menit maka waktu cepat, jika pemeriksaan antara sepuluh dan dua puluh menit maka waktu sedang, dan jika pemeriksaan lebih dari dua puluh menit maka waktu lama.

Tabel 2. Waktu Tunggu

Sumber : Depkes RI, 2007

\begin{tabular}{|c|c|c|c|}
\hline Waktu & Cepat & Sedang & Lama \\
\hline Menit & $<=10$ & $11--20$ & $>=21$ \\
\hline
\end{tabular}

\section{ANALISIS DAN PEMBAHASAN}

\subsection{Sistem Registrasi Pasien}

Website registrasi pasien memiliki beberapa fitur yang diharapkan dapat membantu Klinik dan Rumah Bersalin Melong Asih. Proses aplikasi registrasi pasien dapat dilihat pada Gambar 1. Sistem Registrasi Pasien. 


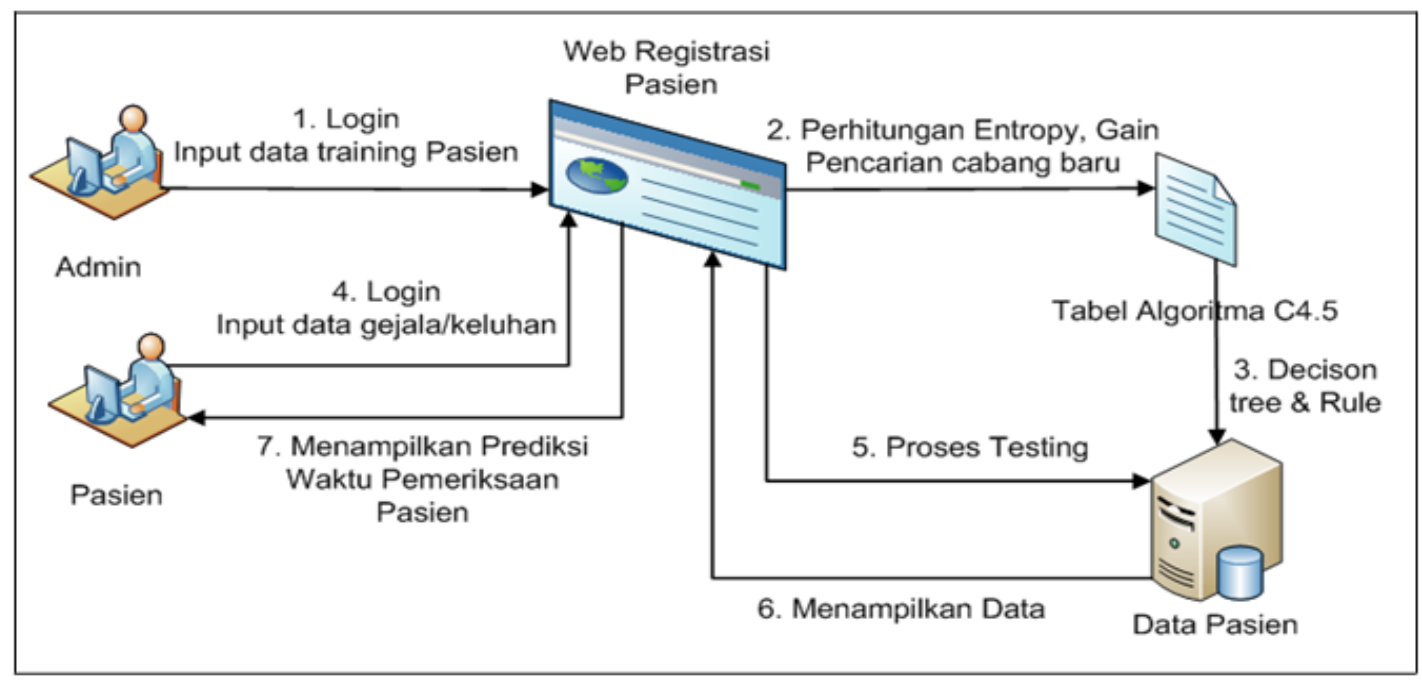

Gambar 1. Sistem Registrasi Pasien

\subsection{Proses Algoritma C4.5 pada Registrasi Pasien}

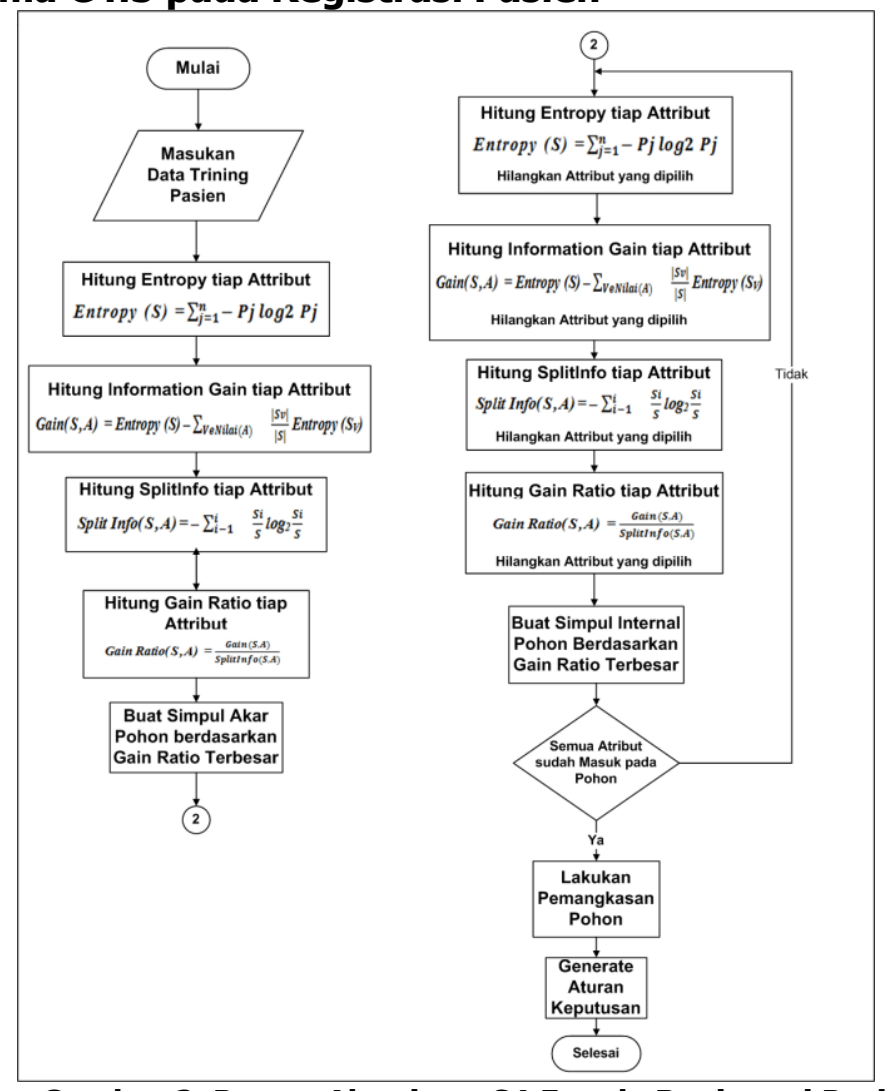

Gambar 2. Proses Algoritma C4.5 pada Registrasi Pasien

Gambar 2 merupakan proses sistem dari aplikasi website registrasi pasien, berikut adalah penjelasan dari setiap tahapan proses yang dilakukan sesuai dengan penomoran yang telah dilakukan : [3]

1. Admin melakukan login pada website untuk memasukan data training pasien. Data training biasanya diambil dari data histori yang pernah terjadi sebelumnya atau disebut data masa lalu dan sudah dikelompokkan dalam kelas-kelas tertentu. 
Tabel 3. Data Training Pasien

\begin{tabular}{|c|c|c|c|}
\hline Nama & $\begin{array}{c}\text { Tujuh Belas Attribut Gejala } \\
\text { Keluhan }\end{array}$ & $\begin{array}{l}\text { Kelas Waktu } \\
\text { Registrasi }\end{array}$ & Jumlah \\
\hline \multirow{3}{*}{$\begin{array}{c}\text { N1 } \\
\text { N2 } \\
\text { N3 } \\
- \\
\text { N100 }\end{array}$} & \multirow{3}{*}{$\begin{array}{c}\text { Kontrol Hamil dan Keluhan, Sakit } \\
\text { Kepala, Batuk/ Demam, Mual, } \\
\text { Muntah, Mulas, Sakit Perut, Sering } \\
\text { Cape, Telat/ Nyeri Haid, Keputihan, } \\
\text { Pendarahan, Keluar Cairan Ketuban, } \\
\text { Keluar Lendir/Flek, Suntik Kb, } \\
\text { Pasang/ Kontrol Iud, Ingin Hamil, } \\
\text { Gerakan Bayi }\end{array}$} & Lama & 12 Kasus \\
\hline & & Sedang & 16 Kasus \\
\hline & & Cepat & 72 Kasus \\
\hline \multicolumn{3}{|c|}{ Jumlah Record Keseluruhan } & 100 \\
\hline
\end{tabular}

Sumber : Data Rekam Medis Klinik Dan Rumah Bersalin Melong Asih

2. Perhitungan dilakukan berdasarkan kasus data pasien untuk menentukan waktu pemeriksaan dilakukan dengan mengimplementasikan Algoritma C4.5 terlihat pada tabel 3. Perhitungan dilakukan berdasarkan 17 gejala keluhan yang dialami oleh pasien. Dengan nilai attribut "Ya atau Tidak". Keluhan pasien ini dijadikan attribut awal dalam implementasi Algoritma C4.5 dan attribut tujuannya adalah waktu pemeriksaan dengan nilai dari attribut waktu pemeriksaan adalah "Cepat", "Sedang", dan "Lama". Cepat artinya kurang dari sepuluh menit, Sedang artinya antara sepuluh dan dua puluh menit, serta Lama artinya lebih dari dua puluh menit.

Tabel 4. Probabilitas Kelas

\begin{tabular}{|c|c|c|}
\hline Kelas & Jumlah & Probabilitas Kelas \\
\hline Lama & 12 & $12 / 100$ \\
\hline Sedang & 16 & $16 / 100$ \\
\hline Cepat & 72 & $72 / 100$ \\
\hline
\end{tabular}

Sumber : Data Training Pasien

Jumlah record keseluruhan $=100$

Distribusi kelas :

$\begin{array}{ll}\text { Kelas Lama } & =12 \\ \text { Kelas Sedang } & =16 \\ \text { Kelas Cepat } & =72\end{array}$

2.1 Menghitung akar dari pohon. Akar diambil dari attribut yang terpilih, dengan cara menghitung nilai Gain dari masing-masing attribut, nilai Gain yang paling tinggi yang menjadi akar pertama. Sebelum menghitung nilai Gain dari attribut, hitung dahulu nilai Entropy seperti pada Gambar 2. Proses Algoritma C4.5 pada proses 1. Untuk menghitung nilai Entropy digunakan rumus :

$$
\operatorname{Entropy}(S)=\sum_{j=1}^{n}-P j \log 2 P j
$$

Keterangan

$\mathrm{S}=$ himpunan (dataset) kasus.

$\mathrm{n}$ = banyaknya partisi $\mathrm{S}$.

$\mathrm{Pj}$ = probabilitas yang di dapat dari kelas dibagi total kasus.

Perhitungan Entropi kelas :

Entropy $(S)=\left(-\frac{12}{100}\left(\log _{2}\left(\frac{12}{100}\right)\right)+\left(-\frac{16}{100}\left(\log _{2}\left(\frac{16}{100}\right)\right)+\left(-\frac{72}{100}\left(\log _{2}\left(\frac{72}{100}\right)\right)=\mathbf{0 . 7 5 4 2}\right.\right.\right.$

Menghitung informasi tiap attribut :

Distribusi kelas attribut Kontrol Hamil \& Keluhan 
Tabel 5. Distribusi Kelas Attribut Kontrol Hamil \& Keluhan

\begin{tabular}{|c|c|c|c|c|}
\hline Outcomes & Lama & Sedang & Cepat & Jumlah Records \\
\hline Tidak & 12 & 16 & 50 & 78 \\
\hline Ya & 0 & 0 & 22 & 22 \\
\hline Jumlah & 2 & 2 & 11 & 100 \\
\hline
\end{tabular}

2.2 Perhitungan Entropi dan Information Gain untuk attribut Kontrol Hamil \& Keluhan, sebagai berikut:

$$
\operatorname{Gain}(S, A)=\operatorname{Entropy}(S)-\sum_{\text {VeNilai }(A)} \frac{|S v|}{|S|} \operatorname{Entropy}\left(S_{V}\right)
$$

$$
\begin{aligned}
\operatorname{Entropy}\left(S_{V}\right) & =\left(-\frac{12}{78}\left(\log _{2}\left(\frac{12}{78}\right)\right)+\left(-\frac{16}{78}\left(\log _{2}\left(\frac{16}{78}\right)\right)+\left(-\frac{50}{78}\left(\log _{2}\left(\frac{50}{78}\right)\right)\right.\right.\right. \\
= & \mathbf{0 , 8 6 3 7}
\end{aligned}
$$

Information Gain $(S, A)=$ Entropy $(S)-\left(\left(\frac{78}{100}\right) * \mathbf{0 , 8 6 3 7}\right)$

$$
\begin{aligned}
& =0,7542-0,6736 \\
& =\mathbf{0 , 0 8 0 5}
\end{aligned}
$$

2.3 Sedangkan perhitungan Split Info dan Gain Ratio untuk attribut Hamil \& Keluhan sebagai berikut:

$$
\text { Split Info }(S, A)=-\sum_{i-1}^{i} \quad \frac{S i}{S} \log _{2} \frac{S i}{S}
$$

Split Info $(S, A)=-\frac{78}{100}\left(\log _{2}\left(\frac{78}{100}\right)\right)=\mathbf{0 , 7 6 0 2}$

$$
\operatorname{Gain} \operatorname{Ratio}(S, A)=\frac{\operatorname{Gain}(S, A)}{\operatorname{SplitInfo}(S, A)}
$$

Gain $\operatorname{Ratio}(S, A)=\frac{0,0805}{0,7602}=\mathbf{0 , 1 0 5 9}$

Hasil perhitungan Information Gain dan Gain Ratio dapat dilihat pada Tabel 6.

Tabel 6. Hasil Perhitungan Information Gain dan Gain Ratio Iterasi 1

\begin{tabular}{|c|c|c|c|c|}
\hline Class & Entropy(S) & Gain(S,A) & SplitInfo(S,A) & $\begin{array}{c}\text { GainRatio(S, } \\
\text { A) }\end{array}$ \\
\hline $\begin{array}{c}\text { kontrol_hamil_keluh } \\
\text { an }\end{array}$ & 0.8637 & 0.0805 & 0.7602 & 0.1059 \\
\hline mual & 0.8207 & 0.0484 & 0.5842 & 0.0828 \\
\hline mulas & 0.6371 & 0.1391 & 0.4022 & 0.3458 \\
\hline pendarahan & 0.6841 & 0.0323 & 0.5842 & 0.0553 \\
\hline $\begin{array}{c}\text { keluar_cairan_ketub } \\
\text { an }\end{array}$ & 0.7309 & 0.0269 & 0.1944 & 0.1384 \\
\hline keluar_lendir_flek & 0.6939 & 0.0881 & 0.2423 & 0.3636 \\
\hline suntik_kb & 0.6935 & 0.0954 & 0.2864 & 0.3331 \\
\hline Pasang_kontrol_iud & 0.7166 & 0.0439 & 0.3274 & 0.1341 \\
\hline Ingin_hamil & $\mathbf{0 . 6 6 2 1}$ & $\mathbf{0 . 1 3 8 4}$ & $\mathbf{0 . 3 6 5 9}$ & $\mathbf{0 . 3 7 8 2}$ \\
\hline gerakan_bayi & 0.4257 & 0.2154 & 0.9044 & 0.2382 \\
\hline
\end{tabular}

2.4 Setelah didapatkan nilai Gain Ratio tiap-tiap attribut, dipilih attribut dengan nilai paling besar. Dari perhitungan pada Tabel 6, didapat Gain Ratio terbesar pada attribut ingin_hamil yaitu $\mathbf{0 . 3 7 8 2}$. Maka attribut ingin_hamil yang di jadikan node. Kemudian bagi node berdasarkan attribut yang terpilih. Decision Tree yang terbentuk ditunjukkan pada Gambar 3. 
ingin_hamil $=$ Ya $($ Lama $=0$, Sedang $=7$, Cepat $=0) \quad$ : Sedang

ingin_hamil $=$ Tidak $($ Lama $=12$, Sedang $=9$, Cepat $=72) \quad:$ ?



Gambar 3. Decision tree iterasi 1

2.5 Pengecekan node dilakukan untuk melihat apakah node sudah murni atau belum. Pemilihan attribut yang baik adalah attribut yang memungkinkan untuk mendapatkan pohon keputusan yang paling kecil ukurannya atau attribut yang bisa memisahkan obyek menurut kelasnya. Jika node belum murni, maka proses membagi node dilakukan kembali secara berulang hingga semua node yang terbentuk menjadi murni dan sudah tidak ada lagi node yang dapat dibagi. Untuk mencari attribut yang menjadi node, dilakukan kembali menghitung informasi tiap attribut yang belum menjadi node. Seperti pada Gambar 2. Proses Algoritma C4.5 pada proses 2.

Contoh perhitungan iterasi 2 yaitu untuk pembagian node.

Tabel 7. Probabilitas Kelas Iterasi 2

\begin{tabular}{|c|c|c|}
\hline Kelas & Jumlah & Probabilitas Kelas \\
\hline Lama & 12 & $12 / 93$ \\
\hline Sedang & 9 & $16 / 93$ \\
\hline Cepat & 72 & $72 / 93$ \\
\hline
\end{tabular}

Jumlah record keseluruhan $=93$

Distribusi kelas :

$\begin{array}{lr}\text { Kelas Lama } & =12 \\ \text { Kelas Sedang } & =9 \\ \text { Kelas Cepat } & =72\end{array}$

Perhitungan Entropi kelas iterasi 2 :

$\operatorname{Entropy}(S)=\left(-\frac{\mathbf{1 2}}{\mathbf{9 3}}\left(\log _{2}\left(\frac{\mathbf{1 2}}{\mathbf{9 3}}\right)\right)+\left(-\frac{9}{\mathbf{9 3}}\left(\log _{2}\left(\frac{9}{\mathbf{9 3}}\right)\right)+\left(-\frac{72}{\mathbf{9 3}}\left(\log _{2}\left(\frac{72}{\mathbf{9 3}}\right)\right)=\mathbf{0 , 6 6 2 1}\right.\right.\right.$

Menghitung informasi tiap attribut.

Distribusi kelas attribut Kontrol Hamil \& Keluhan Iterasi 2

Tabel 8. Distribusi Kelas Attribut Kontrol Hamil \& Keluhan Iterasi 2

\begin{tabular}{|c|c|c|c|c|}
\hline Outcomes & Lama & Sedang & Cepat & Jumlah Records \\
\hline Tidak & 12 & 9 & 50 & 71 \\
\hline Ya & 0 & 0 & 22 & 22 \\
\hline Jumlah & 12 & 9 & 72 & 93 \\
\hline
\end{tabular}

Perhitungan Entropi dan Information Gain untuk attribut Kontrol Hamil \& Keluhan Iterasi 2:

Entropy $\left(S_{V}\right)=\left(-\frac{12}{71}\left(\log _{2}\left(\frac{12}{71}\right)\right)+\left(-\frac{9}{71}\left(\log _{2}\left(\frac{9}{71}\right)\right)+\left(-\frac{50}{71}\left(\log _{2}\left(\frac{50}{71}\right)\right)=\mathbf{0 , 7 7 8 3}\right.\right.\right.$ 
Information Gain $\left.(S, A)=\operatorname{Entropy}(S)-\left(\left(\frac{71}{93}\right) * \mathbf{0 . 7 7 8 3}\right)\right)$

$$
=0,6621-0,5941=\mathbf{0 , 0 6 7 9}
$$

Sedangkan perhitungan Split Info dan Gain Ratio untuk attribut Hamil \& Keluhan Iterasi 2:

Split Info $(S, A)=-\frac{71}{93}\left(\log _{2}\left(\frac{71}{93}\right)\right)=\mathbf{0 , 7 8 9 3}$

Gain Ratio $(S, A)=\frac{0,0679}{0.7893}=\mathbf{0 , 0 8 6}$

2.6 Perhitungan diulangi pada masing-masing attribut yang belum menjadi node. Hasil perhitungan Information Gain dan Gain Ratio tiap attribut pada iterasi kedua dapat dilihat pada Tabel 9.

Tabel 9. Hasil perhitungan information-gain dan gain-ratio tiap attribut pada iterasi 2

\begin{tabular}{|c|c|c|c|c|}
\hline Class & Entropy(S) & Gain(S,A) & SplitInfo(S, $\boldsymbol{A})$ & GainRatio(S,A) \\
\hline kontrol_hamil_keluhan & 0.7783 & 0.0679 & 0.7893 & 0.086 \\
\hline mual & 0.7315 & 0.0407 & 0.6112 & 0.0666 \\
\hline mulas & 0.5335 & 0.1433 & 0.423 & 0.3388 \\
\hline pendarahan & 0.5674 & 0.0364 & 0.6112 & 0.0596 \\
\hline keluar_cairan_ketuban & 0.6362 & 0.0267 & 0.2056 & 0.1299 \\
\hline keluar_lendir_flek & 0.5961 & 0.0916 & 0.2559 & 0.358 \\
\hline suntik_kb & $\mathbf{0 . 5 5 4 4}$ & $\mathbf{0 . 1 3 7 5}$ & $\mathbf{0 . 3 0 2 2}$ & $\mathbf{0 . 4 5 5}$ \\
\hline Pasang_kontrol_iud & 0.5889 & 0.0717 & 0.3451 & 0.2078 \\
\hline Ingin_hamil & 0.6621 & 0 & 0 & 0 \\
\hline gerakan_bayi & 0.4257 & 0.1432 & 0.8398 & 0.1705 \\
\hline
\end{tabular}

3. Setelah didapatkan nilai Gain Ratio tiap attribut, dengan nilai paling besar. Maka dari perhitungan Tabel 9, didapat Gain Ratio terbesar pada attribut suntik_kb yaitu 0,455. Attribut suntik_kb yang di jadikan node. Kemudian dibentuk node berdasarkan attribut yang terpilih. Decision Tree yang terbentuk pada iterasi 2 ditunjukkan pada Gambar 3.

suntik_kb $=$ Ya $($ Lama $=0$, Sedang $=5$, Cepat $=0)$

ingin_hamil $=$ Tidak $($ Lama $=12$, Sedang $=9$, Cepat $=72):$ ?

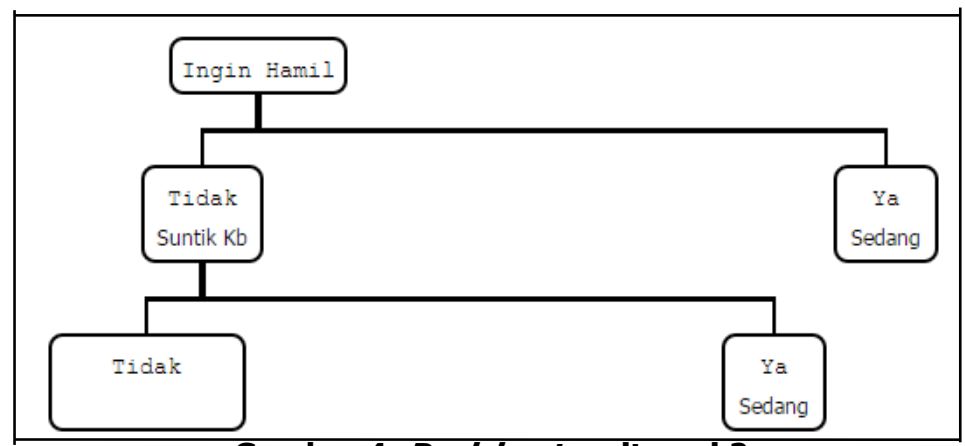

Gambar 4. Decision tree iterasi 2

1.1 Pengecekan dilakukan untuk melihat apakah semua attribut sudah terbentuk pada pohon keputusan. Jika belum, maka diulangi proses 2, jika sudah maka dilanjutkan pada proses berikutnya. Seperti pada iterasi 1 , node dicek apakah node sudah murni atau belum. Jika node sudah murni maka Decision Tree terbentuk. Jika node belum murni maka proses diulangi sampai node murni dan tidak ada lagi node yang dapat dibagi. Decision tree yang terbentuk dari beberapa iterasi setelahnya dapat dilihat pada Gambar 5. 
1.2 Pemangkasan pohon dilakukan untuk menghilangkan cabang-cabang yang tidak perlu.

1.3 Aturan keputusan dibentuk mengikuti pohon yang telah dibentuk sebelumnya.

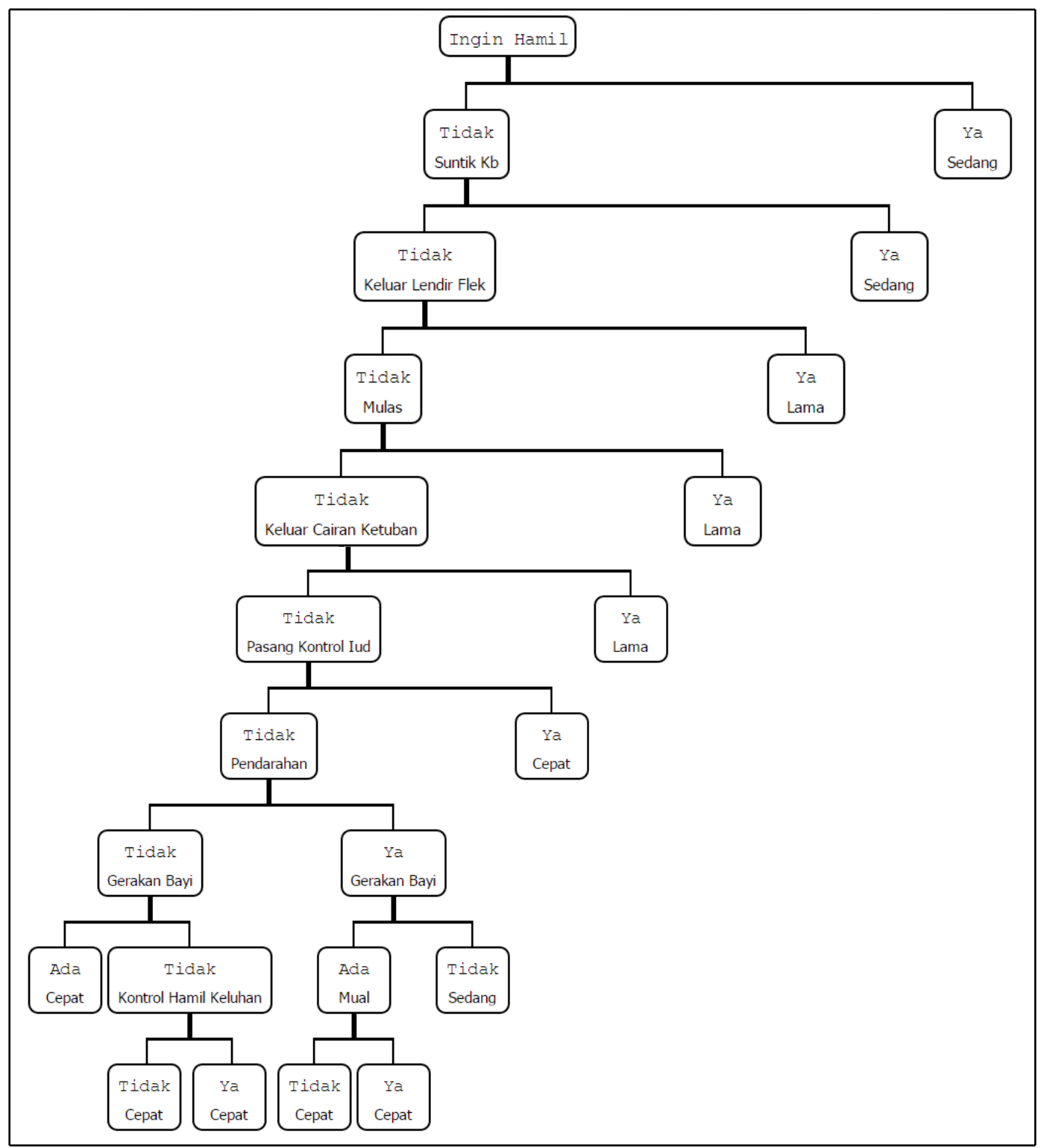

Gambar 5. Decision tree (hasil akhir)

2. Login pada website dilakukan pasien untuk melakukan proses registrasi dengan mengisikan nama, umur, serta gejala serta keluhan yang dialami.

3. Pencocokan hasil data training dari proses Algoritma C4.5 dengan data testing.

4. Data hasil perhitungan Algoritma C4.5 digunakan untuk proses pembentukan keputusan.

5. Pasien mendapatkan waktu pemeriksaan.

\subsection{Pengukuran Kinerja}

Berdasarkan penelitian yang sudah dilakukan untuk mengetahui Precision, Recall, serta Accuracy [3] telah diujikan dari sistem yang sudah dibuat dengan membandingkan dari 70 data training dan 30 data testing dengan proses Algoritma C4.5 dan dicocokan dengan data asli dapat dilihat dari persamaan (5), (6), dan (7) dan pada Tabel 10. 


$$
\begin{aligned}
& \text { Pr ecision }=\left(\frac{d}{b+d}\right) \times 100 \% \\
& \operatorname{Re} \text { call }=\left(\frac{d}{c+d}\right) \times 100 \% \\
& \text { Accuracy }=\left(\frac{a+d}{\text { total sample }}\right) \times 100 \%
\end{aligned}
$$

Tabel 10. Tabel Penilaian C4.5

\begin{tabular}{|c|c|c|}
\hline Tabel Penilaian C4.5 & $\begin{array}{c}\text { DiIdentifikasi Cepat oleh } \\
\text { C4.5 }\end{array}$ & Diidentifikasi Lama oleh C4.5 \\
\hline Keputusan Asli: Lama $=\mathbf{4}$ & $\mathrm{a}=19$ & $\mathrm{~b}=2$ \\
\hline Keputusan Asli: Cepat $\mathbf{2 2}$ & $\mathrm{c}=1$ & $\mathrm{~d}=3$ \\
\hline
\end{tabular}

$a=19 b=2$

$c=1 \quad d=3$

\section{Precision Lama Banding Cepat}

$$
\text { Precision }=\left(\frac{3}{2+3}\right) * 100 \%=60 \%
$$

\section{Recall Lama Banding Cepat}

$$
\text { Recall }=\left(\frac{3}{1+3}\right) * 100 \%=75 \%
$$

\section{Accuracy Lama Banding Cepat}

$$
\text { Accuracy }=\left(\frac{19+3}{4+22}\right) * 100 \%=\mathbf{8 4 . 6 2} \%
$$

Berdasarkan hasil perhitungan diatas, kesalahan prediksi tertinggi berada pada antara keputusan Lama dengan Cepat yaitu mencapai Precision 60 \%, Recall 75 \%, Accuracy 84.62 $\%$.

\section{KESIMPULAN}

Berdasarkan penelitian mengenai Algoritma C4.5 pada registrasi pasien didapat kesimpulan yang diperoleh setelah melakukan penelitian sebagai berikut :

1. Fitur registrasi pasien yang dibangun dengan menerapkan Algoritma C4.5 menggunakan tujuh belas attribut yaitu Kontrol Hamil, Sakit Kepala, dan lima belas jenis keluhan yang sering terjadi. Penerapan Algoritma C4.5 dapat memprediksi waktu pemeriksaan pasien sehingga pasien tidak menunggu lama di Klink dan Rumah Bersalin tersebut untuk mendapatkan giliran periksa.

2. Tingkat akurasi dari implementasi Algoritma klasifikasi C4.5 dipengaruhi oleh beberapa hal seperti jenis, jumlah, isi dataset dan jumlah partisi data set. Partisi data 90:10 merupakan partisi terbaik karena memiliki nilai precision, recall, dan accuracy yang paling tinggi daripada partisi lainnya. Dari hasil uji coba partisi data set semakin besar jumlah partisi data maka dapat menghasilkan jumlah akurasi yang semakin tinggi pula. 


\section{DAFTAR RUJUKAN}

[1] Al Fatta, Hanif., 2007, Analisis Dan Perancangan Sistem Informasi, Andi Yogyakarta.

[2] C. Vercellis., 2009, Bussiness Intelligence : Data Mining and Optimization for Decision Making, John Wiley \& Sons, Ltd.

[3] F. Gorunescu., 2011, Data Mining Concept Model Technique, Springer India.

[4] Han, J., Kamber, M., 2006, Data Mining Concepts and Techniques, Morgan Kaufman Pub San Fransisco.

[5] Kusrini dan Luthfi, E.T., 2009, Algoritma Data Mining, Andi Offset Yogyakarta.

[6] Larose, D. T., 2005, Discovering Knowledge in Data, John Willey \& Sons, Inc New Jersey.

[7] Perpustakaan.Depkes., 2008, Peraturan Menteri Kesehatan Republik Indonesia. Nomor 269/Menkes/Per/Iii/2008. Tentang. Rekam Medis.

[8] Santosa, Budi., 2007, Data Mining Teknik Pemanfaatan Data untuk Keperluan Bisnis, Graha Ilmu Yogyakarta.

[9] Tan, P. N., Steinbach, M., \& Kumar, V., 2005. DATA MINING. New York: Addison Wesley.

[10] Witten, I. H., Frank, E., Hall, M. A., 2011, Data Mining Practical Machine Learning Tools and Techniques (3rd ed), Elsevier USA. 